\title{
Characterizations of the hot blast furnace slag on coal gasification reaction
}

Wenjun Duan, Qingbo Yu*, Junxiang Liu, Limin Hou, Huaqing Xie, Kun Wang, Qin Qin

School of Materials and Metallurgy, Northeastern University, No 11, Lane 3, Wenhua Road, He Ping District, Shenyang 110819, Liaoning, People's Republic of China.

*Corresponding author information:

Telephone/Fax: +86-024-83672216.

E-mail addresses: duanwenjn@163.com (W. J. Duan)

$$
\text { yuqb@smm.neu.edu.cn (Q. B. Yu) }
$$

Mailing address: P.O, Box345, Northeastern University, No11, Lane 3, Wenhua Road, Heping District, Shenyang, Liaoning, P. R. China.

\begin{abstract}
The main objective of this research was to comprehensively investigate the role of the hot blast furnace slag (BFS) played in coal gasification reaction process so as to improve the utilization of BFS waste heat and enhance $\mathrm{H}_{2}$ and $\mathrm{CO}$ content in the syngas. The BFS characterizations, such as the heat carrier, catalyst, reactant, and the sulfide capacity were investigated. The results indicated that about $61 \%$ BFS waste heat could be recovered by coal gasification, and the exergy loss (EXL) of which was only $409 \mathrm{MJ} \cdot \mathrm{t}^{-1}$ slag. Therefore, the BFS was the favorable heat carrier for coal gasification reaction. Besides, the activation energy $\left(E_{a}\right)$ and pre-exponential factor
\end{abstract}


$\left(A_{0}\right)$ for the coal gasification with slag were essentially lower and the reactivity of the coal was significantly improved when the coal was mixed with BFS. The BFS showed a better performance in improving the coal gasification reaction. In the syngas, the $\mathrm{CO}$ and $\mathrm{H}_{2}$ content increased and the $\mathrm{CO}_{2}$ and $\mathrm{CH}_{4}$ content decreased with BFS as heat carrier. In addition, the molten BFS had excellent sulfide capacity

$\left(C_{s}=1.8604 \times 10^{-4}\right)$ known from the theoretical analysis. About $74.45 \%$ of the sulfur and sulfide in Datong (DT) coal was absorbed by BFS so that the emission of the hazardous gases reduced significantly.

\section{Keywords:}

BFS waste heat; coal gasification; heat carrier; reactant; catalyst; sulfide capacity

\section{Introduction}

Nowadays, for the utmost concern on energy saving and emission reduction, developing the advanced techniques to foster clean and sustainable energy sources and reduce energy consumption in industry was extremely urgent and necessary [1-2]. The steel industry was one of the most energy-intensive industries, accounting for about $9 \%$ consumption of the world, with only $17 \%$ of the waste heat recovery rate [3]. Blast furnace slag (BFS), a kind of by-product during the ironmaking process, carried a great deal of high grade heat accounting for $10 \%$ of the waste energy and about $35 \%$ of the high temperature waste heat [4]. For example, in 2012, the pig iron production reached up to 660 million tons in China, which meant that the hot slag 
waste heat was equivalent to 16.5 million tons standard coal $[5,6]$. Therefore, seeking an effective way to utilize the slag waste heat played a vital role in the energy saving for the iron \& steel industry.

Generally, the existent technologies recovering BFS waste heat could be classified into the physical method and the chemical method. As a traditional method, the physical method was widely investigated. However, these methods had not been applied in industry scale [7], due to the fundamental constrains of heat recovery such as low thermal conductivity, crystallizing easily, and the temperature-time discontinuity [8]. Meanwhile, for the remarkable advantages of the chemical method (eg. effectively recovering the latent heat of the BFS, producing high-quality by-product), many researchers had paid much attention to it [2, 9-27].

Kasai and Akiyama et al [9-10] presented the methane steam reforming (MSR) process to recover the hot BFS waste heat. In this process, the BFS waste heat promoted the endothermic reaction of the mixed gas to produce $\mathrm{H}_{2}$ and CO. In 2005, Purwanto [11] supplied a mixture of the $\mathrm{CH}_{4}$ and $\mathrm{CO}_{2}$ to generate the combustible gas by using hot slag waste heat. The results showed that the slag acted as not only the thermal medium but also a good catalyst for promoting the reaction. Although a certain amount of carbon residue generated, increasing the temperature would solve effectively. Maruoka et al [12] designed a new system of the MSR reaction with the aid of a Ni-based catalyst and BFS particles as heat carrier. The $299 \mathrm{~kg}$ hot slag would generate about $106 \mathrm{Nm}^{3}$ of the combustible gas, and about $51 \%$ of the slag thermal energy was utilized. The biomass catalytic gasification was used to recover the BFS 
waste heat by Luo et al [13] in 2012. A continuous moving-bed biomass gasification reactor was proposed to evaluate the feasibility of recovering the BFS waste heat and producing hydrogen rich gas. The results demonstrated the BFS performed as a better catalytic in improving tar cracking, enhancing char gasification and reforming hydrocarbons. In addition, the bio-oil was used in this system to produce combustible gas and recover the waste heat [14]. Sun et al [15] investigated the characteristics of biomass gasification and syngas release behavior using hot slag at the low temperature $\left(200-250^{\circ} \mathrm{C}\right)$. The results showed that the slag increased the production of syngas, and with the mass ratio of wheat straw to slag (1:1), syngas $(0.149 \mathrm{~L} \mathrm{CO}$, $0.036 \mathrm{~L} \mathrm{H}_{2}$ and $0.069 \mathrm{~L} \mathrm{CH}_{4}$ ) could be produced by per gram of wheat straw at $450{ }^{\circ} \mathrm{C}$. Sun et al $[2,16]$ also proposed an integrated method for $\mathrm{CO}_{2} /$ sludge gasification using the hot slag waste heat. The results demonstrated that the BFS was not only a heat carrier, but also an effective desulfurizer. The $\mathrm{SO}_{2}$ concentration at $900{ }^{\circ} \mathrm{C}$ reduced from $164 \mathrm{ppm}$ to $114 \mathrm{ppm}$ by BFS. Zhao [17] investigated the possibility of producing the combustible gas from municipal solid waste using BFS waste heat. In his study, the effect of temperature, gasifying agent and BFS on the gas production were studied at $600-900{ }^{\circ} \mathrm{C}$. Li and $\mathrm{Yu}$ et al [18-23] carried on the thorough research of utilizing coal gasification to produce the syngas with the proposed coal $/ \mathrm{CO}_{2} / \mathrm{slag}$ system. About $0.044 \mathrm{Mt} / \mathrm{Mt}_{\text {slag }}$ of $\mathrm{CO}$ was generated and the thermal-to-chemical conversion efficiency reached to 35\%. Duan and Yu et et al [24] also investigated the process of the coal $/ \mathrm{H}_{2} \mathrm{O}(\mathrm{g}) / \mathrm{slag}$ to produce hydrogen-rich gas. The optimal operating parameters were obtained by thermodynamic analysis and the hydrogen concentration reached to 
62.63\%. Meanwhile, an integrated system combining a physical method with chemical method was proposed to recover the BFS waste heat and produce the hydrogen-rich gas [25-27].

It could be seen from the studies mentioned above that the high-quality BFS waste heat could be recovered by chemical method effectively. In whole process, the BFS not only acted as the heat carrier, but also influenced the chemical reaction rate and the composition of the syngas. Therefore, in order to get the best results of the chemical method, it was necessary to comprehensively investigate the function of BFS in the chemical reaction. Motivated by the above situations, the characterizations of hot BFS as heat carrier, catalyst, and reactants were investigated and the results were obtained. Meanwhile, the characterization of the sulfide capacity of BFS was also studied to realize the hazardous gas releasing in gasification process.

\section{Experimental and methods}

2.1 Raw materials and sample preparation

\subsubsection{Raw materials}

In the study, five types of industrial coal samples with different ranks were involved. The coal types were selected according to the content of volatile matter, ash, and fixed carbon $[19,21]$. The proximate and ultimate analyses of the coal samples were shown in Table 1. The Datong (DT) and Fuxin (FX) were classified as high-quality coal, the Fushun (FS) and Shennan (SN) were classified as medium-quality coal, and the Dezhou (DZ) was classified as low-quality coal. 


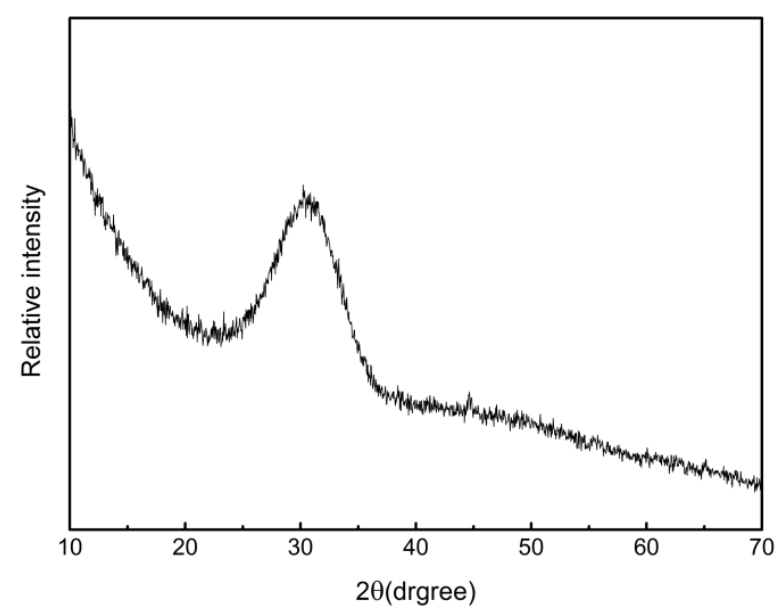

Fig. 1 XRD results of the water quenched BFS

The water quenched BFS, from an iron and steel company, was used in this investigation, with the chemical compositions of $41.21 \% \mathrm{CaO}, 34.38 \% \mathrm{SiO}_{2}, 8.22 \%$ $\mathrm{MgO}, 11.05 \% \mathrm{Al}_{2} \mathrm{O}_{3}, 2.78 \% \mathrm{Fe}_{2} \mathrm{O}_{3}, 0.35 \% \mathrm{TiO}_{2}$ and some minor constituents of titanium, sulfur and phosphor oxides. To confirm the glassy phase of the quenched slags, XRD (X-ray diffraction) analysis was carried out, as shown in Fig. 1. Sun et al $[28,29]$ also used this method to confirm the state of the BFS. The XRD test was performed in a $2 \theta$ degree range of $10^{\circ}-70^{\circ}$ with a speed of $4^{\circ} / \mathrm{min}$, where $\theta$ was the angle between the incident ray and the scattered plane and intensity of the reflected ray was shown in Y-axis. The average specific heat of the slag was $1.21 \mathrm{~kJ} \cdot(\mathrm{kg} \cdot \mathrm{K})^{-1}$. The gasification agent was $\mathrm{CO}_{2}$ with the purity more than $99.9 \%$. 
Table 1 The proximate and elemental analyses of the coal

\begin{tabular}{|c|c|c|c|c|c|}
\hline Coal & DT & FX & FS & $\mathrm{SN}$ & $\mathrm{DZ}$ \\
\hline \multicolumn{6}{|c|}{ Proximate analysis (wt\%) } \\
\hline Moisture, wt $\%$ & 9.05 & 3.13 & 1.83 & 2.30 & 4.96 \\
\hline Volatile matter, wt $\%$ & 38.38 & 32.78 & 28.72 & 26.38 & 4.82 \\
\hline Fixed carbon, wt $\%$ & 38.42 & 34.79 & 20.81 & 22.85 & 19.11 \\
\hline Ash, wt $\%$ & 14.15 & 29.30 & 48.64 & 48.47 & 71.11 \\
\hline \multicolumn{6}{|c|}{ Ultimate analysis (wt\%) } \\
\hline Carbon & 64.53 & 52.27 & 39.05 & 42.59 & 21.57 \\
\hline Hydrogen & 3.746 & 4.204 & 3.489 & 3.379 & 0.710 \\
\hline Nitrogen & 0.956 & 1.09 & 1.13 & 0.74 & 0.19 \\
\hline Sulfur & 0.561 & 1.210 & 0.619 & 0.967 & 0.457 \\
\hline Oxygen & 7.007 & 8.796 & 5.242 & 1.554 & 1.003 \\
\hline
\end{tabular}

\subsubsection{Sample preparation}

(1) Thermo-gravimetric experiment sample preparation

To produce thermo-gravimetric experiment samples, the coal and BFS samples were dried in the air at $105{ }^{\circ} \mathrm{C}$ for $24 \mathrm{~h}$, crushed and ground to $0.16 \mathrm{~mm}$. Then, the crushed samples were thoroughly mixed using a ball mill. Two samples containing 5 mg coal were used to conduct the gasification reaction in the crucible: the one, the pure coal sample; the other one, the mixture of the coal and BFS with the mass ratio of $1: 2$ 
(2) Gasification reaction sample preparation

The coal gasification reaction experiments were conducted in a tube-type setup. The reactor was made of a high-purity alumina tube $(99.9 \%)$, whose bottom was closed. The inner diameter of the reactor was $30 \mathrm{~mm}$. The BFS particles were placed into the tube layer by layer. The height of the slag was about $500 \mathrm{~mm}$. The BFS particles were obtained by the method of rotary cup atomizer (RCA). The schematic diagram of the experimental apparatus was shown in Fig. 2. Based on the Liu's experimental results $[20,30-31]$, the technical parameters of the rotary cup diameter was $130 \mathrm{~mm}$, the rotate speed of rotary cup was $1000 \mathrm{rpm}$, and the flow rate of the molten BFS was $0.5 \mathrm{t} / \mathrm{h}$ in the granular procedure. The granulation process could be seen from Supplemental Fig. S1. The BFS particles with the diameter about $1 \mathrm{~mm}$ was produced and used in this experiment. Meanwhile, the coal samples were crushed and ground to about $0.16 \mathrm{~mm}$, and transported into the tube by $\mathrm{CO}_{2}$.

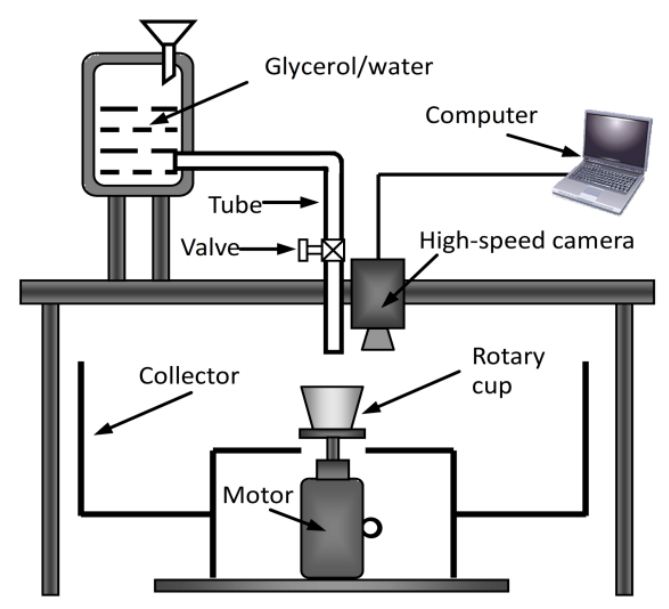

Fig. 2 The schematic diagram of the molten slag granulation experimental apparatus

\subsection{Characterization techniques}

The schematic of the experimental apparatus was shown in Fig. 3. A 
thermo-gravimetric analyzer (NETZSCH, STA409PC, the working temperature up to $1500{ }^{\circ} \mathrm{C}$ and the maximum heating rate up to $50{ }^{\circ} \mathrm{C} / \mathrm{min}$ ) was used in the reactivity tests of the coal gasification reaction with/without BFS. In the experiment, the coal samples were placed in the corundum crucible and the flow rate of $\mathrm{N}_{2}$ stream was 30 $\mathrm{mL} \cdot \mathrm{min}^{-1}$ as the protective gas. As shown in Fig. 4, the char preparation and gasification process were carried out consecutively with the thermo-gravimetric analyzer. The coal sample mixed with/without BFS was placed in the crucible. And then, pyrolysis occurred as the temperature rising from ambient to $950{ }^{\circ} \mathrm{C}$ at 20 ${ }^{\circ} \mathrm{C} /$ min under the $\mathrm{N}_{2}$ atmosphere. The sample was maintained at $950{ }^{\circ} \mathrm{C}$ for 30 min to complete the pyrolysis. After then, the sample was heated to the desired temperature at a heating rate of $20^{\circ} \mathrm{C} / \mathrm{min}$ under the $\mathrm{N}_{2}$ atmosphere. Then, the $\mathrm{N}_{2}$ was replaced by $\mathrm{CO}_{2}\left(30 \mathrm{~mL} \cdot \mathrm{min}^{-1}\right)$ to complete the coal gasification reaction. During the char preparation and the gasification process, the mass change of the sample could be measured by the thermo-gravimetric analyzer and recorded by a computer.

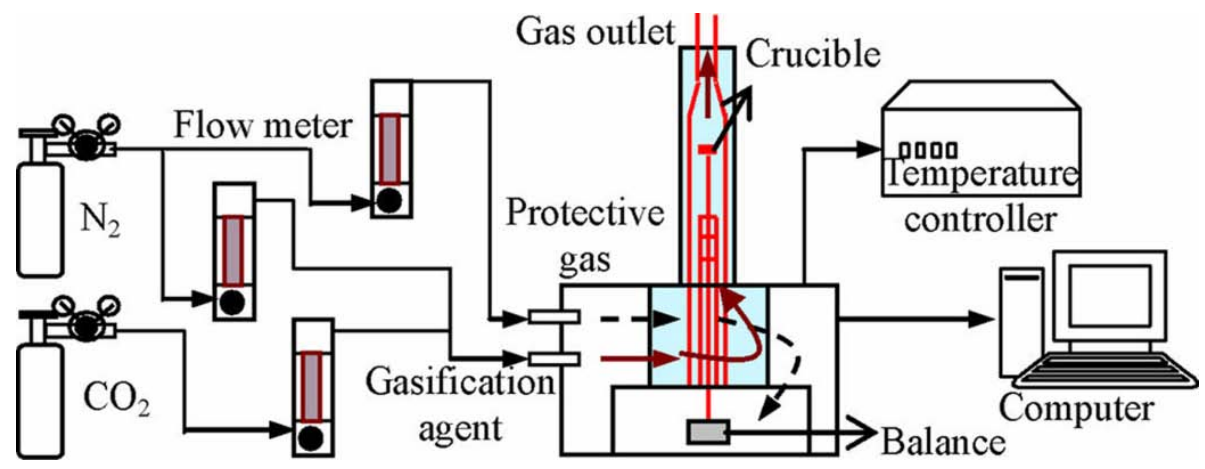

Fig. 3 The schematic of the thermo-gravimetric experimental apparatus

The carbon conversion of the coal without BFS was expressed as:

$$
x(t)=\frac{w_{0}-w_{t}}{w_{0}-w_{a s h}}
$$


where, $x(t)$ was the carbon conversion at the reaction time $t, \% ; w_{0}$ was the original mass of the char, mg; $w_{t}$ was the instantaneous mass of the char at any reaction time $t$, $\mathrm{mg} ; w_{\text {ash }}$ was the mass of the ash in the char, mg.

However, the carbon conversion calculation method of pure coal was different from that of the coal sample mixed with the BFS. The reason was that the weight of the BFS changed with the temperature increasing. The carbon conversion of coal with BFS was expressed as [19, 23]:

$$
x(t)=\left[\left(\frac{w_{c 0}-w_{c t}}{w_{c 0}-w_{c \infty}}\right)-\left(\frac{w_{s 0}-w_{s t}}{w_{s 0}-w_{s \infty}}\right) \times \frac{m}{m+1}\right] \times(1+m) \times 100 \%
$$

where, $w_{c 0}$ was the original mass of the char and BFS, mg; $w_{c t}$ was the instantaneous mass of coal char and BFS at a reaction time $t, \mathrm{mg} ; w_{c \infty}$ was the final mass of the char and BFS, mg; $w_{s 0}$ was the original mass of the BFS, mg; $w_{s t}$ was the instantaneous mass of slag at a reaction time $t$, mg; $w_{s \infty}$ was the final mass of the BFS, mg; $m$ was the ratio of the BFS to coal char.

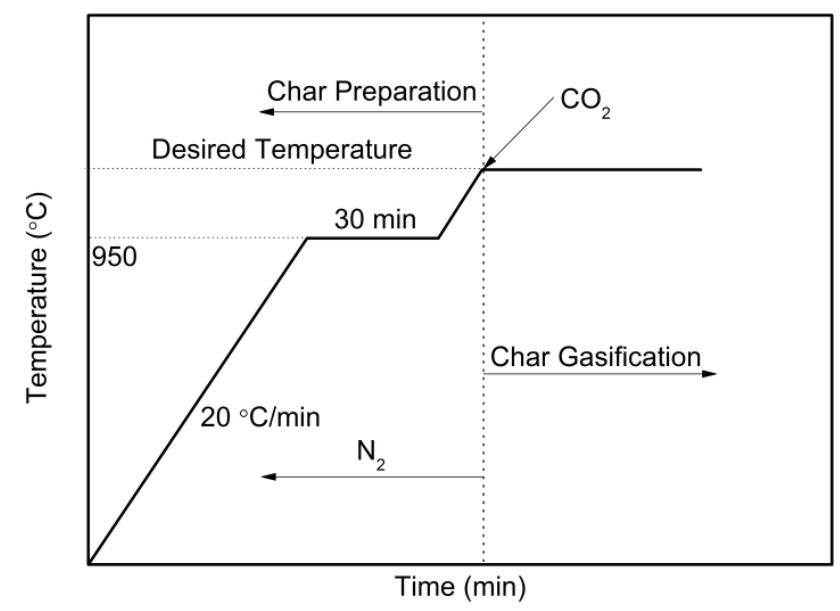

Fig. 4 The diagram of the thermo-gravimetric experimental procedure 


\section{Results and discussions}

\subsection{The heat carrier characterization}

The coal gasification was an intensely endothermic process, and the heat had to be supplied continuously by syngas combustion or electrical supply to this process to ensure the appropriate reaction temperature. However, in the coal gasification using hot BFS as heat carrier to produce syngas, the heat needed was entirely provided by hot slag. Therefore, under this condition, the gasification process proceeded smoothly while the hot BFS waste heat was recovered effectively. The schematic diagram of the BFS waste heat recovery system and the gasifier were shown in Supplemental Fig. S2 and Supplemental Fig. S3, respectively.

For evaluating the utilization of the BFS waste heat, the Enthalpy-exergy diagram (Thermodynamic compass) method [27, 32] was used. Meanwhile, some assumptions were proposed in the theoretical calculation: 1). the temperature of the BFS entered into the system was $1500{ }^{\circ} \mathrm{C}$ and the tapping temperature was $200{ }^{\circ} \mathrm{C} ; 2$ ). the efficiency of recovering the BFS waste heat in the gasifier and boiler were $100 \%$; 3 ). the slag granulating process was proceeding in the gasifier without the thermal loss. The Fig. 5 showed the Enthalpy-exergy diagram of the coal gasification reaction for recovering the waste heat from hot BFS. It can be seen from the Fig. 5, the exergy loss (EXL) of the BFS waste heat was only $409 \mathrm{MJ} \cdot \mathrm{t}^{-1}$ slag, which was only about half of the traditional physical recycling method [27]. The high-quality waste heat of the slag was utilized effectively by coal gasification, and it was the advantage of the chemical recycling method for the hot slag waste heat recovery. In addition, the 
results demonstrated that more than $61 \%$ of the hot BFS waste heat was used by the coal gasification process. Based on the Steel Statistical Yearbook 2014, about $1.649 \times 10^{3}$ million tonnes of steel were produced in the whole world in 2014 . In this process, about $0.495 \times 10^{3}$ million tonnes of slag were also generated, from which $7.786 \times 10^{8}$ GJ waste heat was discharged. According to the above analysis and the Duan's results [25], about $4.749 \times 10^{8}$ GJ waste heat (equivalent to 16.23 million tonnes standard coal) could be used for coal gasification reaction to produce syngas with high calorific value. About $7.233 \times 10^{10} \mathrm{~m}^{3} \mathrm{CO}_{2}$ were captured and about $5.94 \times 10^{10} \mathrm{~m}^{3}$ syngas was generated. Overall, the BFS waste heat could ensure the coal gasification reaction to proceed effectively, for achieving the objective of energy saving and emission reduction.

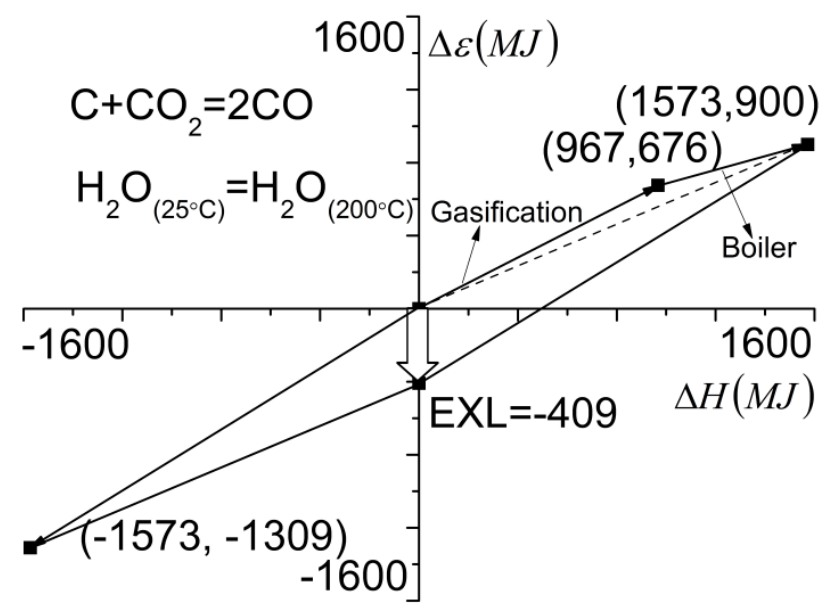

Fig. 5 The Enthalpy-exergy diagram of the coal gasification reaction for recovering the waste heat from hot BFS

\subsection{The catalyst characterization}

In order to understand the reactivity of the coal gasification, the carbon conversion, reaction rate, reactivity index and the kinetic parameters (activation energy, $E_{a}$; 
pre-exponential factor, $A_{0}$.) were studied.

From Fig. 6 and Fig. 7, we could see the effect of the BFS on carbon conversion and reaction rate of the coal gasification. It could be observed from the Fig. 6(a) and Fig. 6(b), the carbon conversion with BFS (coal/slag ratio=1:2) was higher than that without slag (coal/slag ratio=1:0). The time required for $100 \%$ of carbon conversion with BFS was shorter than that of pure coal. Such as the DT coal gasification reaction at $950{ }^{\circ} \mathrm{C}$, the time for $100 \%$ of carbon conversion with BFS was about 18.9 min, whereas that was about 27.6 min without BFS. Meanwhile, it could be observed from the Fig. 7(a) and Fig. 7(b), the reaction rate with BFS was also higher than that without BFS under the same reaction temperature. The time required for the maximum reaction rate with BFS was shorter than that without slag. At $1150{ }^{\circ} \mathrm{C}$, the maximum reaction rate with $\mathrm{BFS}$ was $0.8703 \mathrm{~min}^{-1}$ with a corresponding time of 1.3 min, whereas that without slag was only $0.3737 \mathrm{~min}^{-1}$ with a corresponding time of $1.4 \mathrm{~min}$.
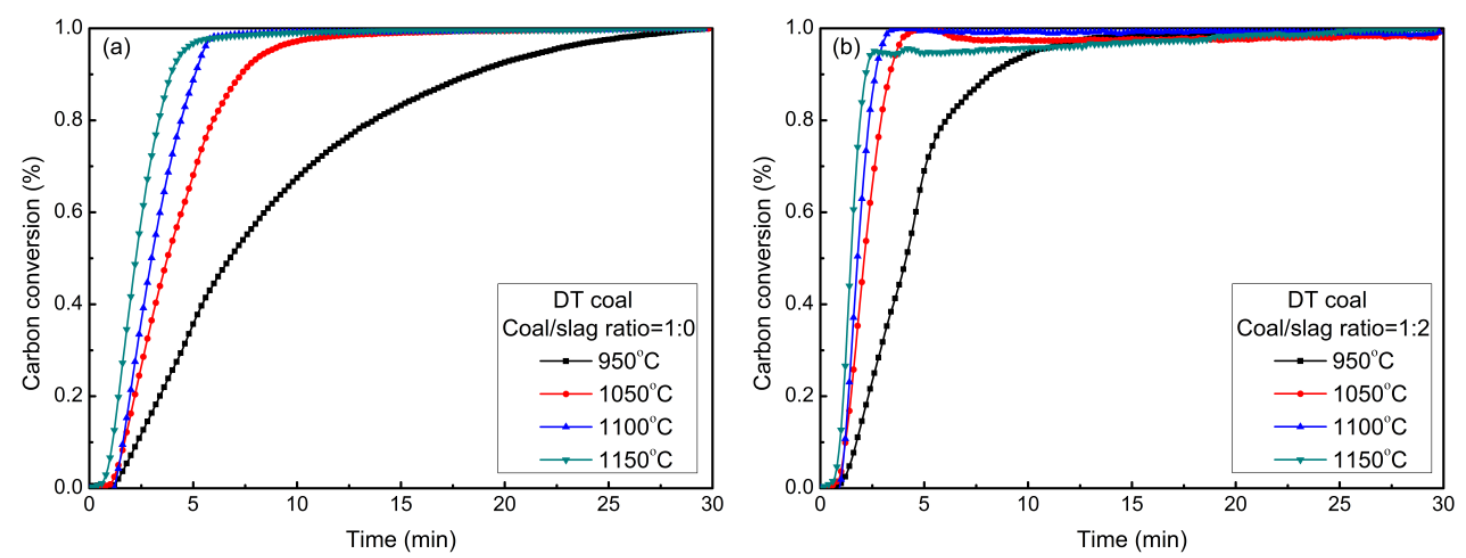

Fig. 6 The effect of the slag on carbon conversion at different temperatures (a) without slag, coal $/$ slag ratio $=1: 0($ b) with slag, coal/slag ratio $=1: 2$

The reactivity index was a good indicator to illustrate the coal gasification reaction 
[27, 33-34]. The reactivity index $\left(R_{0.5}\right)$ was defined as the reciprocal of the double time necessary for $50 \%$ of the carbon conversion, as shown in Eq. (3).

$$
R_{0.5}=\frac{0.5}{\tau_{0.5}}
$$

where, $\tau_{0.5}$ was the time for $50 \%$ of the carbon conversion, min.
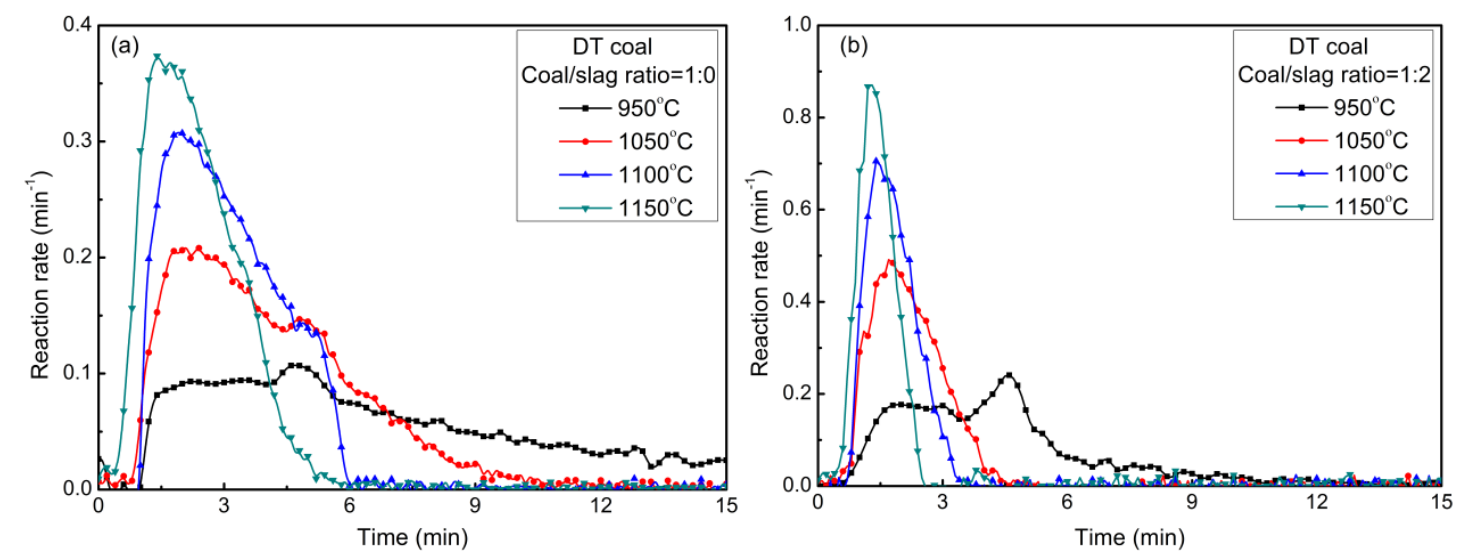

Fig. 7 The effect of the slag on reaction rate at different temperatures (a) without slag, coal/slag ratio $=1: 0$ (b) with slag, coal/slag ratio=1:2

Table 2 The variation of the reactivity index of the coal gasification reaction with reaction temperature and coal/slag ratio $\left(\mathrm{min}^{-1}\right)$

\begin{tabular}{cccccccccccccc}
\hline & \multicolumn{2}{c}{ DT } & \multicolumn{2}{c}{ FX } & \multicolumn{2}{c}{ FS } & \multicolumn{2}{c}{ SN } & \multicolumn{2}{c}{ DZ } \\
Temperature $\left({ }^{\circ} \mathrm{C}\right)$ & & & & & & & & & & \\
& $1: 0$ & $1: 2$ & $1: 0$ & $1: 2$ & $1: 0$ & $1: 2$ & $1: 0$ & $1: 2$ & $1: 0$ & $1: 2$ \\
\hline \multirow{2}{*}{950} & 0.074 & 0.122 & 0.068 & 0.120 & 0.056 & 0.116 & 0.032 & 0.100 & 0.027 & 0.081 \\
1050 & 0.135 & 0.238 & 0.125 & 0.218 & 0.114 & 0.200 & 0.086 & 0.152 & 0.080 & 0.112 \\
1100 & 0.167 & 0.278 & 0.163 & 0.254 & 0.156 & 0.238 & 0.135 & 0.192 & 0.127 & 0.177 \\
1150 & 0.227 & 0.333 & 0.223 & 0.320 & 0.200 & 0.313 & 0.161 & 0.263 & 0.149 & 0.194 \\
\hline
\end{tabular}

It could be observed from the Table 2, the reactivity index of the coal gasification reaction increased with the temperature increasing. At the same temperature, the 
reactivity index of the coal gasification reaction with BFS was higher than that without it. For example, the reactivity index of DT coal without and with BFS were $0.074 \mathrm{~min}^{-1}$ and $0.122 \mathrm{~min}^{-1}$ at $950{ }^{\circ} \mathrm{C}$, respectively. Meanwhile, as the catalyst, the BFS was applied widely in all kinds of the coal rank (from DT coal to DZ coal). The reactivity index of the all kinds of the coal increased significantly when it was mixed with BFS.

Ultimately, we reached the conclusion that the BFS could act as the catalyst for the gasification reaction of all kinds of coal. It was because that the content of $\mathrm{Ca}$ and $\mathrm{Mg}$ in the BFS was high, and these melts' alkali and alkaline catalyzed the gasification reaction. The effect of these melts on gasification reaction was proved by numerous researchers [35-37]. Thus, the BFS could be used for lower temperature gasification to overcome the slow reaction rate. The more high-quality BFS waste heat could be recovered in gasification process.

The kinetic study was done isothermally with different coal to slag ratio at $950{ }^{\circ} \mathrm{C}$, $1050{ }^{\circ} \mathrm{C}, 1100{ }^{\circ} \mathrm{C}$ and $1150{ }^{\circ} \mathrm{C}$. The mass change in the coal gasification was continuously monitored at $1 \mathrm{~s}$ interval. The reaction rate could be calculated by the following equation based on the carbon conversion.

$r=\frac{d x}{d t}=k(T) f(x)$

where, $k(T)$ was the constant of the intrinsic surface reaction rate; $f(x)$ was a function that described the change in the surface area during the reaction. In the kinetic study, it was crucial to select an appropriate function of $f(x)$. Based on the Li's results [27], the Eq. (5) was suitable for the coal gasification reaction using BFS as heat carrier. 


$$
f(x)=n(1-x)[-\ln (1-x)]^{\frac{n-1}{n}}
$$

where, $n$ was 2 in the coal gasification without BFS; $n$ was described as the Eq. (6) with BFS as heat carrier in coal gasification.

$$
n=\frac{m_{\text {coal }}+m_{\text {slag }}}{m_{\text {coal }}}
$$

where, $m_{\text {coal }}$ was the initial mass of coal in the sample, mg; $m_{\text {slag }}$ was the initial mass of BFS in the sample, mg.

The activation energy $\left(E_{a}\right)$ and pre-exponential factor $\left(A_{0}\right)$ could be calculated from the Arrhenius law, with the kinetics of this process described as

$$
k(T)=A_{0} \exp \left(-\frac{E_{a}}{R T}\right)
$$

where, $R\left(8.314 \times 10^{-3} \mathrm{~kJ} \cdot \mathrm{K}^{-1} \cdot \mathrm{mol}^{-1}\right)$ was the gas constant.

By taking the logarithm of both sides of Eq. (7), the Eq. (8) could be obtained

$$
\ln k(T)=\ln A_{0}-\frac{E_{a}}{R} \times \frac{1}{T}
$$

Based on the data for weight loss at a given temperature, kinetic parameters $A_{0}$ and $E_{a}$ were estimated from the intercept and slop respectively using a plot $\ln k(T)$ versus $1 / T$

Based on the kinetic analysis above, the gasification reaction rate equation and kinetic parameters for the coal gasification reaction with/without BFS were obtained, as shown in Table 3. It could be seen from Table 3, the $E_{a}$ and $A_{0}$ obtained for the coal gasification reaction with BFS were lower than that of the coal without BFS. According to the transition state theory, the $A_{0}$ represented the activation entropy and was related to the material structure [38-39]. The lower $A_{0}$ was, the greater conversion of the initial organic matter was in the coal. All above meant that the presence of BFS 
was beneficial to the coal gasification reaction, no matter what the quality of the coal was.

Table 3 The gasification reaction rate equation and kinetic parameters for coal gasification reaction with/without BFS

\begin{tabular}{ccccccccccc}
\hline $\begin{array}{c}\text { Gasification rate } \\
\text { equation }\end{array}$ & $r=\frac{d x}{d t}=2 A_{0} \exp \left(-\frac{E_{a}}{R T}\right)(1-x)[-\ln (1-x)]^{1 / 2}$ & $r=\frac{d x}{d t}=n A_{0} \exp \left(-\frac{E_{a}}{R T}\right)(1-x)[-\ln (1-x)]^{n-1 / n}$ \\
\hline Coal/slag ratio & & & $1: 0$ & & & & & $1: 2$ & & \\
& $\mathrm{DT}$ & $\mathrm{FX}$ & $\mathrm{FS}$ & $\mathrm{SN}$ & $\mathrm{DZ}$ & $\mathrm{DT}$ & $\mathrm{FX}$ & $\mathrm{FS}$ & $\mathrm{SN}$ & $\mathrm{DZ}$ \\
$E_{a}(\mathrm{~kJ} / \mathrm{mol})$ & 112 & 115 & 119 & 124 & 130 & 87 & 90 & 92 & 78 & 81 \\
$A_{0}\left(\mathrm{~min}^{-1}\right)$ & 4806 & 5725 & 6325 & 9848 & 10754 & 965 & 826 & 673 & 325 & 317 \\
\hline
\end{tabular}

\subsection{The reactant characterization}

In the present work, the coal gasification with ceramic ball and BFS were respectively conducted to evaluate the function of the BFS. The product distribution of coal gasification with ceramic ball and BFS as heat carrier were shown in Fig. 8. It was clear that there was significant effect on the coal gasification reaction with BFS. Compared to the gasification with ceramic ball, the $\mathrm{CO}$ and $\mathrm{H}_{2}$ content increased remarkably and the $\mathrm{CO}_{2}$ and $\mathrm{CH}_{4}$ content decreased. It meant that the BFS was a reactant in the gasification reaction to improve the product distribution. It was consistent with the results reported by some researchers $[13,15,17,40]$.

Metal oxides could prevent the formation of stable chemical structures in 
hydrocarbons, speed up the degradation of hydrocarbons, weaken the C-C bond and thereby reduce the activation energy of the gasification reaction [41-42]. It could also be assumed that the metals weakened the intermolecular interaction of the polymeric chains, at the same time, promoted the retro-aldol cleavage and condensation of the syngas [43]. Therefore, primary water gas reaction $\left(\mathrm{C}+\mathrm{H}_{2} \mathrm{O} \leftrightharpoons \mathrm{CO}+\mathrm{H}_{2} \Delta H_{\mathrm{r}}=131 \mathrm{~kJ} / \mathrm{mol}\right)$ and methane reforming reaction $\left(\mathrm{CH}_{4}+\mathrm{H}_{2} \mathrm{O} \leftrightharpoons \mathrm{CO}+3 \mathrm{H}_{2} \quad \Delta H_{\mathrm{r}}=206 \mathrm{~kJ} / \mathrm{mol}\right)$ were the main factors responsible for the production of $\mathrm{H}_{2}$ and $\mathrm{CO}$ [44]. In addition, due to the $\mathrm{CaO}$ in $\mathrm{BFS}, \mathrm{CO}_{2}$ in the production syngas was absorbed and converted to $\mathrm{CaCO}_{3}$, thus it promoted the water gas shift reaction $\left(\mathrm{CO}+2 \mathrm{H}_{2} \mathrm{O} \leftrightharpoons \mathrm{CO}_{2}+\mathrm{H}_{2} \Delta H_{\mathrm{r}}=-41 \mathrm{~kJ} / \mathrm{mol}\right)$ and enhanced the $\mathrm{H}_{2}$ concentration. Meanwhile, $\mathrm{Fe}_{2} \mathrm{O}_{3}$ in the BFS also had influence on the coal gasification, the oxidation of $\mathrm{CH}_{4}$ to $\mathrm{CO}_{2}$ in the reaction with $\mathrm{Fe}_{2} \mathrm{O}_{3}$ was preferred [24]. In conclusion, the BFS showed a better performance in improving the coal gasification reaction as a reactant.

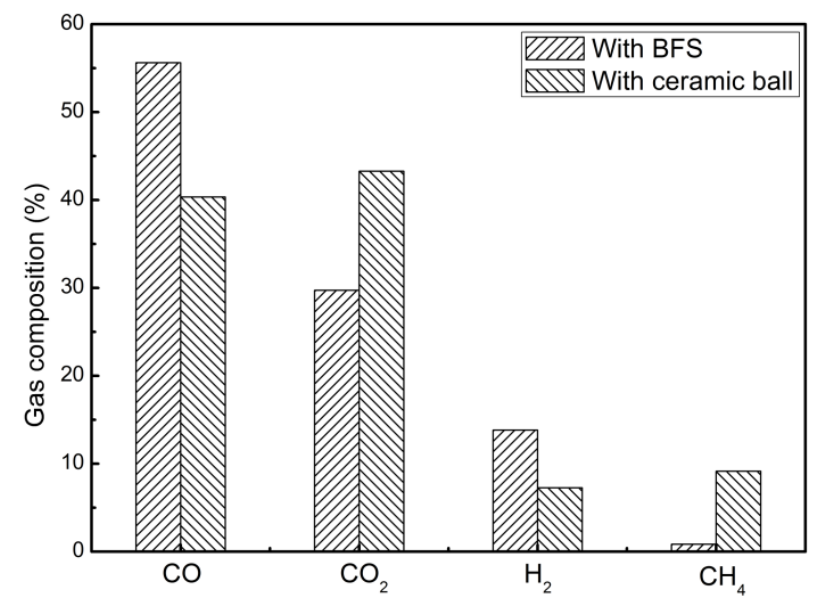

Fig. 8 The product distribution of coal gasification with ceramic ball and BFS as heat carrier 


\subsection{The sulfide capacity characterization}

During the utilization of the coal, the releasing of the hazardous gases gave rise to the severe environmental issue, especially the $\mathrm{SO}_{2}$. In the coal gasification reaction with BFS as heat carrier, the BFS could absorb a certain amount of the sulfide in the coal, and reduce the $\mathrm{SO}_{2}$ emission. Therefore, it was necessary to study the sulfide capacity of the molten BFS in order to control the $\mathrm{SO}_{2}$ emission in the coal gasification process.

In the molten $\mathrm{BFS}$, the generation of the sulfur was related to the oxygen partial pressure $\left(P_{\mathrm{O}_{2}}\right)$. The sulfur existed in $\mathrm{S}^{2-}$ during the $P_{\mathrm{O}_{2}} \leq 0.1 \mathrm{~Pa}$, and in $\mathrm{SO}_{4}{ }^{2-}$ during $P_{\mathrm{O}_{2}} \geq 10 \mathrm{~Pa}$. The formation reactions were as follows $[2,45]$ :

$$
\begin{array}{ll}
\frac{1}{2} S_{2}+\left(O^{2-}\right)=\frac{1}{2} O_{2}+\left(S^{2-}\right) & \left(P_{O_{2}} \leq 0.1 \mathrm{~Pa}\right) \\
\frac{1}{2} S_{2}+\frac{3}{2} O_{2}+\left(O^{2-}\right)=\left(\mathrm{SO}_{4}{ }^{2-}\right) & \left(P_{O_{2}} \geq 10 \mathrm{~Pa}\right)
\end{array}
$$

In molten $\mathrm{BFS}$, the actual oxygen pressure was lower than $10^{-3} \mathrm{~Pa}$, so the sulfur was in $\mathrm{S}^{2-}[46,47]$.

For the certain reaction temperature and the slag compositions, the sulfide capacity could be expressed as:

$$
C_{S}=w(S) \times\left[\frac{P_{O_{2}}}{P_{S_{2}}}\right]^{1 / 2}=K^{\Theta} \times\left(\frac{a_{O^{2-}}}{\gamma_{S^{2-}}}\right)
$$

where, the $C_{S}$ was the sulfide capacity of the molten BFS.

Based on the analysis above, the sulfide capacity of the molten BFS could be obtained by the following equation:

$\lg C_{S}=12.0 \Lambda-11.9$

Where, $\Lambda$ was the optical basicity of the BFS. Considering the influence of the 
temperature, the Eq. (12) could be converted to Eq. (13).

$$
\lg C_{S}=\frac{22690-54640 \Lambda}{T}+43.6 \Lambda-25.2
$$

The optical basicity $(\Lambda)$ was described by the Eq. (14)

$$
\Lambda=\sum_{B=1}^{n} x_{B} \Lambda_{B}
$$

where, $\Lambda_{B}$ was the optical basicity of the oxides, the theoretical optical basicity values was calculated using Pauling electronegativities by Gaskell [48] in the present work and shown in Table 4. $x_{B}$ was the mole percentage of the cation in the oxides.

$$
x_{B}=n_{O} x_{B}^{\prime} / \sum n_{O} x_{B}^{\prime}
$$

where, $x_{B}^{\prime}$ was the mole percentage of the oxides; $n_{O}$ was the numbers of the oxygen atom in the oxide.

Table 4 The optical basicity values for various oxides

\begin{tabular}{cccccccc}
\hline Oxide & $\mathrm{CaO}$ & $\mathrm{MgO}$ & $\mathrm{SiO}_{2}$ & $\mathrm{Al}_{2} \mathrm{O}_{3}$ & $\mathrm{TiO}_{2}$ & $\mathrm{MnO}$ & $\mathrm{FeO}$ \\
\hline$\Lambda_{B}$ & 1.0 & 0.78 & 0.48 & 0.605 & 0.61 & 0.59 & 0.51 \\
\hline
\end{tabular}

Based on the equations and parameters above, the optical basicity of the BFS in this experiment was 0.6808 . The sulfide capacity of the molten BFS was about $1.8604 \times 10^{-4}$. Duan et al [25] performed the technological calculation for synergistic system of BFS waste heat recovery and carbon resources reduction. Their results showed that about $44.55 \mathrm{~kg} / \mathrm{t}_{\text {slag }}$ DT coal containing about $0.25 \mathrm{~kg}$ sulfur was consumed by the waste heat of one ton BFS at $1500{ }^{\circ} \mathrm{C}$ in the system. Therefore, about $74.45 \%$ of the sulfur and sulfide in the coal was absorbed by molten BFS. The molten BFS could reduce the sulfur emission effectively in the coal gasification reaction. 


\section{Conclusions}

In this work, the BFS characterizations of heat carrier, catalyst, reactant and the sulfide capacity in the coal gasification reaction were successfully researched by experiments and theoretical calculation. In the coal gasification using BFS as heat carrier, the heat of the endothermic reaction required was fully provided by hot BFS. About $61 \%$ heat of the slag was recovered and the latent heat was utilized effectively (the EXL of the waste heat was only $409 \mathrm{MJ} \cdot \mathrm{t}^{-1}$ slag). The activation energy of the gasification reaction was reduced by the BFS so the reactivity and reaction rate of the gasification was significantly increased. For the gasification production, compared with the coal gasification reaction without the BFS, the $\mathrm{CO}$ and $\mathrm{H}_{2}$ content increased remarkably, and the content of combustible gases in the syngas increased significantly. Meanwhile, about $74.45 \%$ of the sulfur and sulfide produced in the DT coal gasification process was absorbed by molten BFS. The emission of the hazardous gases in the gasification process was controlled effectively.

\section{Nomenclature}

$w_{c 0}=$ the original mass of the char and BFS;

$w_{c t}=$ the instantaneous mass of coal char and BFS at a reaction time $t$;

$w_{c \infty}=$ the final mass of the char and BFS;

$w_{s 0}=$ the original mass of the BFS;

$w_{s t}=$ the instantaneous mass of slag at a reaction time $t$;

$w_{s \infty}=$ the final mass of the BFS; 
$m=$ the ratio of the BFS to coal char;

$R_{0.5}=$ the reactivity index, $\min ^{-1}$

$\tau_{0.5}=$ the time necessary for the carbon conversion reached to $50 \%$, min;

$k(T)=$ the constant of the intrinsic surface reaction rate;

$f(x)=$ a function that described the change in the surface area during the reaction;

$E_{a}=$ the activation energy;

$A_{0}=$ the pre-exponential factor;

$m_{\text {coal }}=$ the initial mass of coal in the sample;

$m_{\text {slag }}=$ the initial mass of BFS in the sample;

$C_{S}=$ the sulfide capacity of the molten BFS;

$\Lambda=$ the optical basicity of the BFS;

$x_{B}=$ the optical of the oxides;

$x_{B}^{\prime}=$ the mole percentage of the oxides;

$n_{O}=$ the numbers of the oxygen atom in the oxide.

\author{
Abbreviations \\ $\mathrm{BFS}=$ Blast furnace slag \\ MSR reaction $=$ Methane steam reforming reaction \\ $\mathrm{EXL}=$ Exergy loss \\ DT coal $=$ Datong coal \\ FX coal $=$ Fuxin coal \\ FS coal $=$ Fushun coal
}


$\mathrm{SN}$ coal $=$ Shennan coal

DZ coal $=$ Dezhou coal

$\mathrm{RCA}=$ Rotary cup atomizer

\section{Acknowledgements}

This research was supposed by The National Natural Science Foundation of China (51274066, 51304048), The National Science Foundation for Post-doctoral Scientists of China (2013M541240, 2015M571322), The National Key Technologies R\&D Program of China (2013BAA03B03), The Fundamental Research Funds for the Central Universities (N130402019).

\section{References}

[1]. Zhang H, Wang H, Zhu X, Qiu YJ, Li K, Chen R, Liao Q. A review of waste heat recovery technologies towards molten slag in steel industry. Applied Energy 2013; 112: 956-966

[2]. Sun YQ, Zhang ZT, Liu LL, Wang XD. Integrated carbon dioxide/sludge gasification using waste heat from hot slags: syngas production and sulfur dioxide fixation. Bioresource Technology 2015; 181: 174-182.

[3]. Cahyono RB, Rozhan AN, Yasuda N, Nomura T, Hosokai S, Kashiwaya Y, Akiyama T. Integrated coal-pyrolysis tar reforming using steelmaking slag for carbon composite and hydrogen production. Fuel 2013; 109: 439-444.

[4]. Wu JJ, Wang H, Zhu X, Liao Q, Ding B. Centrifugal granulation performance of 
liquid with various viscosities for heat recovery of blast furnace slag. Applied Thermal Engineering 2015; 89: 494-504.

[5]. Steel Statistical Yearbook 2013. Worldsteel Association. Available online: http://www.worldsteel.org/publications/bookshop/product-details. Steel-Statistic al-Yearbook-2013 PRODUCT SSY2013 .html(accessed on 5 December 2014).

[6]. Barati M, Esfahani S, Utigard TA. Energy recovery from high temperature slags. Energy 2011; 36: 5440-5449.

[7]. Ma GY, Cai JJ, Zheng WW, Dong H. Analytical research on waste heat recovery and utilization of China's iron \& steel industry. Energy Procedia 2012; 14: $1022-1028$

[8]. Sun YQ, Zhang ZT, Liu LL, Wang XD. Heat recovery from high temperature slags: a review of chemical methods. Energies 2015; 8: 1917-1935.

[9]. Kasai E, Kitajima T, Akiyama T, YAGI J, Saito F. Rate of methane-steam reforming molten BF slag for heat recovery a chemical reaction on from molten the surface of slag by using a chemical reaction. ISIJ International 1997; 37(10): 1031-1036.

[10]. Shimada T, Kochura V, Akiyama T, Kasai E, Yagi J. Effects of slag compositions on the rate of methane-steam reaction. ISIJ International 2001; 41: 111-115.

[11]. Purwanto H, Akiyama T. Hydrogen production from biogas using hot slag. International Journal of Hydrogen Energy 2006; 31: 491-495.

[12]. Maruoka N, Mizuochi T, Purwanto H, Akiyama T. Feasibility study for recovering waste heat in the steelmaking industry using a chemical recuperator. 
ISIJ International 2004; 44(2): 257-262.

[13]. Luo SY, Zhou YM, Yi CJ. Hydrogen-rich gas production from biomass catalytic gasification using hot blast furnace slag as heat carrier and catalyst in moving-bed reactor. International Journal of Hydrogen Energy 2012; 37: 15081-15085.

[14]. Luo SY, Yi CJ, Zhou YM. Bio-oil production by pyrolysis of biomass using hot blast furnace slag. Renewable Energy 2013; 50: 373-377.

[15]. Sun YQ, Zhang ZT, Seetharaman S, Liu LL, Wang XD. Characteristics of low temperature biomass gasification and syngas release behavior using hot slag. RSC Advances 2014; 4: 62105-62114.

[16]. Sun YQ, Nakano J, Liu LL, Wang XD, Zhang ZT. Achieving waste heat to energy through sewage sludge gasification using hot slags: syngas production. Scientific Reports 2015; 5.

[17]. Zhao LM, Wang H, Qing S, Liu HL. Characteristics of gaseous product from municipal solid waste gasification with hot blast furnace slag. Journal of Natural Gas Chemistry 2010; 19: 403-408.

[18]. Li P, Yu QB, Qin Q, Liu JX. Adaptability of coal gasification in molten blast furnace slag on coal samples and granularities. Energy \& Fuels 2011; 25(12): $5678-5682$

[19]. Li P, Yu QB, Qin Q, Lei W. Kinetics of $\mathrm{CO}_{2}$ coal gasification in molten blast furnace slag. Industrial \& Engineering Chemistry Research 2012; 51(49): $15872-15783$.

[20]. Liu JX, Yu QB, Li P, Du WY. Cold experiments on ligament formation for blast 
furnace slag granulation. Applied Thermal Engineering 2012; 40: 351-357.

[21]. Li P, Yu QB, Xie HQ, Qin Q, Wang $\mathrm{K} . \mathrm{CO}_{2}$ gasification rate analysis of Datong coal using slag granules as heat carrier for heat recovery from blast furnace slag by using a chemical reaction. Energy \& Fuels 2013; 27(8): 4810-4817.

[22]. Li P, Yu QB, Qin Q, Du W. The effects of slag compositions on the coal gasification reaction in molten blast furnace slag. Energy Sources, Part A 2014; 36: 73-79.

[23]. Li P, Lei W, Wu B, Yu QB. $\mathrm{CO}_{2}$ gasification rate analysis of coal in molten blast furnace slag-For heat recovery from molten slag by using a chemical reaction. International Journal of Hydrogen Energy 2015; 40: 1607-1615.

[24]. Duan WJ, Yu QB, Xie HQ, Qin Q, Zuo ZL. Thermodynamic analysis of hydrogen-rich gas generation from coal/steam gasification using blast furnace slag as heat carrier. International Journal of Hydrogen Energy 2014; 39: 11611-11619.

[25]. Duan WJ, Yu QB, Zuo ZL, Qin Q, Li P, Liu JX. The technological calculation for synergistic system of BF slag waste heat recovery and carbon resources reduction. Energy Conversion and Management 2014; 87: 185-190.

[26]. Duan WJ, Yu QB, Wang K, Qin Q, Hou LM, Yao X, Wu TW. ASPEN Plus simulation of coal integrated gasification combined blast furnace slag waste heat recovery system. Energy Conversion and Management 2015; 100: 30-36.

[27]. Duan WJ, Yu QB, Lei W, Chen W, Yu QB, Wang K, Qin Q. Thermodynamic analysis of blast furnace slag waste heat-recovery system integrated with coal 
gasification. JOM 2015; 67: 1079-1085.

[28]. Sun YQ, Shen HW, Wang H, Wang XD, Zhang ZT. Experimental investigation and modeling of cooling processes of high temperature slags. Energy 2014; 76: $761-767$.

[29]. Sun YQ, Zhang ZT, Liu LL, Wang XD. Multi-stage control of waste heat recovery from high temperature slags based on time temperature transformation curves. Energies 2014; 7: 1673-1684.

[30]. Liu JX, Yu QB, Duan WJ, Qin Q. Experimental investigation on ligament formation for molten slag granulation. Applied Thermal Engineering 2014; 73: 886-891.

[31]. Liu JX, Yu QB, Qin Q. Numerical study on film disintegration by centrifugal atomization using rotating cup. Powder Metallurgy 2013; 56(4): 288-294.

[32]. Ishida M. Thermodynamic made comprehensible. New York: Nova Science Publishers Inc, 2002

[33]. Qi XJ, Guo X, Xue LC, Zheng CG. Effect of iron on Shenfu coal char structure and its influence on gasification reactivity. Journal of Analytical and Applied Pyrolysis 2014; 110: 401-407.

[34]. Zhan XL, Jia J, Zhou ZJ, Wang FC. Influence of blending methods on the co-gasification reactivity of petroleum coke and lignite. Energy Conversion and Management 2011; 52(4): 1810-1814.

[35]. Ismail K, Yarmo MA, Taugiq-Yap YH, Ahmad A. The effect of particle size of $\mathrm{CaO}$ and $\mathrm{MgO}$ as catalysts for gasification of oil palm empty fruit bunch to 
produce hydrogen. International Journal of Hydrogen Energy 2012; 37: $3639-3644$.

[36]. Maneerung T, Kawi S, Wang Chi-Hwa. Biomass gasification bottom ash as a source of $\mathrm{CaO}$ catalyst for biodiesel production via transesterification of palm oil. Energy Conversion and Management 2015; 92: 234-243.

[37]. Li DL, Tamura M, Nakagawa Y, Tomishige K. Metal Catalysts for steam reforming of tar derived from the gasification of lignocellulosic biomass. Bioresource Technology 2015; 178: 53-64.

[38]. Shatokha VI, Sokolovskaya IV. Study on effect of coal treatment with blast furnace slag on char reactivity in air. Ironmaking and Steelmaking 2012; 39(6): $439-445$.

[39]. Shatokha VI, Sokolovskaya IV. Effect of coal treatment with molten blast furnace slag on char properties. Ironmaking and Steelmaking 2013; 40(8): 635-637.

[40]. Wang ZH, Zhou JH, Wang QH, Fan JR, Cen KF. Thermodynamic equilibrium analysis of hydrogen production by coal based on $\mathrm{Coal} / \mathrm{CaO} / \mathrm{H}_{2} \mathrm{O}$ gasification system. International Journal of Hydrogen Energy 2006; 31: 945-952.

[41]. Rustamov VR, Abdullayev KM, Samedov EA. Biomass conversion to liquid fuel by two-stage thermochemical cycle. Energy Conversion and Management 1998; 39(9): 869-875.

[42]. Shen BX, Qin L. Study on MSW catalytic combustion by TGA. Energy Conversion and Management 2006; 47(11-12):1429-1437. 
[43]. Rustamov VR, Abdullayev KM, Samedov EA. Biomass conversion to liquid fuel by two-stage thermochemical cycle. Energy Conversion and Management 1988; 39: 869-875.

[44]. Luo SY, Xiao B, Guo XJ, Hu ZQ, Liu SM, He MY. Hydrogen-rich gas from catalytic steam gasification of biomass in a fixed bed reactor: Influence of particle size on gasification performance. International Journal of Hydrogen Energy 2009; 34: 1260-1264.

[45]. Susaki K, Maeda M, Sano N. Sulfide capacity of Cao-CaF $-\mathrm{SiO}_{2}$. Metallurgical Transactions B 1990; 21: 121-129.

[46]. Azami T, Hibiya T. Interpreting the oxygen partial pressure around a molten silicon drop in terms of its surface tension. Journal of Crystal Growth 2001; 233(3): 417-424.

[47]. Parry G, Ostrovski O. Wettability of solid metals by molten $\mathrm{CaO}-\mathrm{SiO}_{2}-\mathrm{Al}_{2} \mathrm{O}_{3}$ slag. Metallurgical and Materials Transactions B 2008; 29B: 681-689.

[48]. Gaskell DR. On the correlation between the distribution of phosphorous between slag metal and the theoretical optical basicity of the slag. Transactions of the Iron and Steel Institute of Japan 1982; 22: 997-100. 


\section{TABLE CAPTION}

Table 1 The proximate and elemental analyses of the coal

Table 2 The variation of the reactivity index of the coal gasification reaction with reaction temperature and coal/slag ratio $\left(\mathrm{min}^{-1}\right)$

Table 3 The gasification reaction rate equation and kinetic parameters for coal gasification reaction with/without BFS

Tab le 4 The optical basicity values for various oxides 


\section{FIGURE CAPTION}

Fig. 1 XRD results of the water quenched BFS

Fig. 2 The schematic diagram of the molten slag granulation experimental apparatus

Fig. 3 The schematic diagram of the thermo-gravimetric experimental apparatus

Fig. 4 The diagram of the thermo-gravimetric experimental procedure

Fig. 5 The Enthalpy-exergy diagram of the coal gasification reaction for recovering the waste heat from hot BFS

Fig. 6 The effect of the slag on carbon conversion at different temperatures (a) without slag, coal/slag ratio=1:0 (b) with slag, coal/slag ratio=1:2

Fig. 7 The effect of the slag on reaction rate at different temperatures (a) without slag, coal $/$ slag ratio $=1: 0$ (b) with slag, coal $/$ slag ratio $=1: 2$

Fig. 8 The gas compositions of the coal gasification with ceramic ball and BFS as heat carrier 